\title{
PEMANFAATAN LIMBAH BATANG JAGUNG SEBAGAI ADSORBEN ALTERNATIF PADA PENGURANGAN KADAR KLORIN DALAM AIR OLAHAN (TREATED WATER)
}

\author{
Fatimah Rahmayani, Siswarni MZ \\ Departemen Teknik Kimia, Fakultas Teknik, Universitas Sumatera Utara, \\ Jl. Almamater Kampus USU, Medan 20155, Indonesia \\ Email : azzure_dealova@yahoo.com
}

\begin{abstract}
Abstrak
Berbagai hasil dari limbah pertanian yang memiliki kadar selulosa tinggi dapat dimanfaatkan sebagai adsorben alternatif, salah satunya adalah adsorben dari limbah batang jagung, dimana batang jagung kering biasanya menjadi limbah dan dibakar di ladang setelah panen yang tentunya mengakibatkan pencemaran lingkungan. Keadaan ini menjadi motivasi untuk memproduksi bahan yang bernilai tambah dari limbah batang jagung yaitu sebagai adsorben alternatif untuk mengurangi kadar klorin dalam air olahan, proses pembuatan adsorben alternatif ini dilakukan dengan menggunakan aktivator asam sulfat dengan variasi konsentrasi 1\%, 3\% dan $5 \%$ dengan ukuran partikel 50 mesh dan 70 mesh pada suhu pemanasan $105{ }^{\circ} \mathrm{C}$ dengan variasi waktu adsorbsi 30, 60 dan 90 menit. Kondisi yang paling baik dari aktivasi yang diperoleh adalah pada konsentrasi aktivator 5\%, ukuran partikel 70 mesh dan waktu adsorbsi 90 menit, dimana bilangan iodin yang diperoleh adalah $482 \mathrm{mg} / \mathrm{L}$ dan kadar klorin yang terserap adalah 96,08\%. Dari penelitian yang dilakukan dapat disimpulkan bahwa limbah batang jagung dapat dimanfaatkan sebagai adsorben untuk mengurangi kadar klorin dalam air olahan.
\end{abstract}

Kata kunci : adsorben alternatif, batang jagung, aktivasi secara kimia

\begin{abstract}
Various result of agricultural waste that contain high cellulose can be used as an alternative adsorbent. One of them was derived from dried corn stalks which traditionally burnt after harvest that lead to environmental pollution. It is necessary to produce the value-added materials from corn stalks waste as an alternative adsorbent to reduce the level of chlorine in treated water. This process was performed by using various level of sulfuric acid concentration 1\%, 3\% and 5\%, particles size 50 and 70 mesh in $105^{\circ} \mathrm{C}$ with adsorbtion time 30,60 and 90 minutes. The most favorable activation result was obtained at 5\% concentration, with particle size 70 mesh, adsorbtion time 90 minutes and the iodine value was $482 \mathrm{mg} / \mathrm{l}$ with level of adsorbed chlorine was 96,08\%. Based on this findings, we concluded that the corn stalks waste can be used as an alternative adsorbent in reducing the level of chlorine in treated water.
\end{abstract}

Keywords: alternative adsorbents, corn stalks, chemical activation

\section{Pendahuluan}

Melihat pentingnya pemakaian karbon aktif dalam industri sebagai adsorben dan harganya cukup mahal, maka sebagai adsroben alternatif dimanfaatkanlah limbah batang jagung. Penelitian ini adalah tentang pemanfaatan limbah batang jagung sebagai adsorben alternatif pada pengurangan kadar klorin dalam air olahan (treated water). Metode pembuatan arang aktif yang digunakan adalah metode aktivasi kimiawi dengan aktivator asam sulfat $\left(\mathrm{H}_{2} \mathrm{SO}_{4}\right)$.

Penelitian mengenai adsorben alternatif sebelumnya telah banyak dilakukan, diantaranya adalah :

1. Penelitian mengenai adsorben alternatif dimana karbon aktif dibuat dari alang alang dengan hasil uji terhadap kadar abu, kadar air, bilangan iodine, angka asam, massa jenis dan luas spesifik telah memenuhi persyaratan spesifik sebagai sebuah karbon aktif [7].

2. Penelitian tentang pembuatan karbon aktif dari kulit kacang tanah dimana kondisi terbaik daya serapnya terhadap larutan iodine yaitu pada suhu pemanasan $450{ }^{\circ} \mathrm{C}$ dengan lama pemanasan 90 menit dan daya adsorbsi sebesar $1296 \mathrm{mg} / \mathrm{g}$ [6].

3. Penelitian pemanfaatkan limbah batang jagung sebagai adsorben untuk menyerap ion Tembaga (II) menghasilkan kondisi optimum yang diperoleh pada kondisi aktivasi $300^{\circ} \mathrm{C}$ dan waktu aktivasi selama 1 jam [2].

Permasalahan pokok yang akan dijawab dalam penelitian ini adalah mampukah adsorben dari batang jagung mengurangi kadar 
klorin yang terdapat dalam air olahan (treated water). Untuk itu dirumuskanlah beberapa permasalahan, bagaimana pengaruh massa dan waktu kontak adsorben dari batang jagung terhadap kualitas air olahan (treated water). Bagaimana pengaruh variasi konsentrasi aktivator $\mathrm{H}_{2} \mathrm{SO}_{4}$ yang dilakukan terhadap bilangan iodin dari adsorben batang jagung yang dibuat.

\section{Teori}

Adsorben merupakan zat padat yang dapat menyerap komponen tertentu dari suatu fase fluida. Kebanyakan adsorben adalah bahan bahan yang sangat berpori dan adsorbsi berlangsung terutama pada dinding - dinding pori atau pada letak - letak tertentu didalam partikel itu. Oleh karena pori - pori biasanya sangat kecil maka luas permukaan dalam menjadi beberapa orde besaran lebih besar daripada permukaan luar dan bisa mencapai 2000 $\mathrm{m} / \mathrm{g}$. Adsorben yang digunakan secara komersial dikelompokkan menjadi dua yaitu kelompok polar dan non polar

1. Adsorben polar disebut juga hydrophilic

2. Adsorben non polar disebut juga hydrophobic

Menurut IUPAC (Internationl Union of Pure and Applied Chemical) ada beberapa klasifikasi pori yaitu :

a. Mikropori : diameter $<2 \mathrm{~nm}$

b. Mesopori : diameter $2-50 \mathrm{~nm}$

c. Makropori : diameter $>50 \mathrm{~nm}$ [3].

Bahan baku pembuatan karbon aktif diperoleh dari darah, daging dan tulang hewan. Dari tumbuh - tumbuhan misalnya kayu, kayu lunak, batang jagung, lumut laut, kulit buah kapas, jerami, biji buah - buahan, kulit buah pala, limbah penyulingan tumbuh - tumbuhan dan lain sebagainya. [5]

Untuk setiap unsur klor aktif seperti klor tersedia bebas dan klor tersedia terikat tersedia analisa-analisa khusus. Namun untuk praktikum biasa hanya klor aktif (residu) ditentukan melalui suatu analisa; klor tersedia bebas dan klor tersedia terikat didapatkan melalui grafik klorinasi breakpoint. Klor aktif dapat dianalisa melalui titrasi iodometri atau melalui titrasi klorimetri dengan DPD. Analisa iodometri agak sederhana dan murah tetapi tidak sepeka metode DPD.

Selain metode diatas yang digunakan di laboratorium juga ada metode kasar yang digunakan dilapangan, yaitu memakai alat komparator dengan ortotolidin.

Klor aktif akan membebaskan iodin $\mathrm{I}_{2}$ dari kalium Iodida (KI) jika $\mathrm{pH}<8$ (terbaik adalah $\mathrm{pH}<3$ atau 4), sesuai dengan reaksi berikut,
$\mathrm{OCl}^{-}+2 \mathrm{KI}+2 \mathrm{HAs} \rightarrow \mathrm{I}_{2}+2 \mathrm{KAs}+\mathrm{Cl}^{-}+2 \mathrm{H}_{2} \mathrm{O}$

$\mathrm{NH}_{2} \mathrm{Cl}+2 \mathrm{KI}+2 \mathrm{HAs} \rightarrow \mathrm{I}_{2}+\mathrm{KAs}+\mathrm{KCl}+$

$\mathrm{NH}_{4} \mathrm{As}$

$\mathrm{I}_{2}+\mathrm{Kanji} \longrightarrow$ Warna Biru

$\mathrm{I}_{2}+2 \mathrm{Na}_{2} \mathrm{~S}_{2} \mathrm{O}_{3} \longrightarrow \mathrm{Na}_{2} \mathrm{~S}_{4} \mathrm{O}_{6}+2 \mathrm{NaI}$

Sebagai indikator digunakan kanji yang merubah warna sesuatu larutan yang mengandung iodin menjadi biru. Untuk menentukan jumlah klor aktif, iodin yang telah dibebaskan oleh klor aktif tersebut dititrasikan dengan larutan standard natriumtiosulfat sesuai reaksi diatas. Titik akhir titrasi dinyatakan dengan hilangnya warna biru dari larutan. Asam asetik (HAs) $\mathrm{CH}_{3} \mathrm{COOH}$ harus digunakan untuk menurunkan $\mathrm{pH}$ larutan sampai 3 atau 4 [1].

Adsorbsi adalah suatu proses pemisahan dimana komponen dari suatu fluida berpindah kepermukaan zat padat yang menyerap (adsorben).

Teknik aktivasi yang terutama digunakan oleh operasi - operasi komersial adalah dengan teknik aktivasi kimia (chemical activation) dan teknik karbonasi (steam activation). Sebagai mana sebutannya, aktivasi kimia biasanya digunakan pada bahan-bahan yang berupa gambut dan bahan - bahan berbahan dasar kayu. Bahan dasar direaksikan dengan dehydrating agent, berupa pospor pentoksida $\left(\mathrm{P}_{2} \mathrm{O}_{5}\right)$ atau besi klorida $\left(\mathrm{ZnCl}_{2}\right)$ yang dicampurkan dalam bentuk pasta lalu dipanaskan pada temperature tingga yaitu sekita $500-800{ }^{\circ} \mathrm{C}$ untuk mengaktivasi karbon. Hasil karbon yang telah diaktivasi kemudian dicuci, dikeringkan dan digiling sesuai ukuran yang dinginkan. Karbon aktif yang di produksi dengan teknik aktivasi ini umumnya memiliki pori-pori yang luas dan sangat ideal untuk menyerap bahan - bahan dengan molekul yang besar.

Teknik karbonasi (steam activation) umumnya digunakan untuk mengaktivasi batu bara dan cangkang kelapa. Aktivasi dilakukan pada temperatur $800-1100{ }^{\circ} \mathrm{C}$ dengan mengalirkan uap panas jenuh. Reaksi yang terjadi berupa :

$$
\mathrm{C}+\mathrm{H}_{2} \mathrm{O} \longrightarrow \mathrm{H}_{2}+\mathrm{CO}+175440 \mathrm{~kJ} / \mathrm{kgmol}
$$

Reaksi yang berlangsung adalah reaksi endotermik akan tetapi temperatur dipertahankan dengan pembakaran $\mathrm{CO}$ dan $\mathrm{H}_{2}$ yang diproduksi. $2 \mathrm{CO}+\mathrm{O}_{2} \longrightarrow 2 \mathrm{CO}_{2}-393790 \mathrm{~kJ} / \mathrm{kgmol}$ $2 \mathrm{H}_{2}+\mathrm{O}_{2} \longrightarrow \mathrm{H}_{2} \mathrm{O}-396650 \mathrm{~kJ} / \mathrm{kgmol}$

Karbon aktif yang dihasilkan dengan teknik ini memiliki pori - pori yang cukup baik dan ideal digunakan untuk mengadsorbsi komponen-komponen berfase cair maupun uap.

Daya adsorbsi dari karbon aktif dapat ditetapkan dengan menggunakan adsorbsi isotherm. Adsorbsi isotherm adalah sebuah 
persamaan yang menghubungkan antara padatan yang akan diadsorbsi dengan adsorben.

Parameter yang dapat menunjukkan kualitas arang aktif adalah daya adsorbsi arang aktif terhadap larutan Iod. Daya adsorbsi arang aktif terhadap iod memiliki korelasi dengan luas permukaan arang aktif. Dimana semakin besar angka iod maka semakin besar kemampuan dalam mengadsorbsi adsorbat atau zat terlarut . Salah satu metode yang digunakan dalam analisis daya adsorbsi arang aktif terhadap iod adalah dengan metode titrasi iodometri. Kereaktifan dari arang aktif dapat dilihat dari kemampuannya mengadsorbsi substrat. Daya adsorbsi tersebut dapat ditunjukkan dengan besarnya angka iod (iodin number) yaitu angka yang menunjukkan seberapa besar adsorben dapat mengadsorbsi iod. Semakin besar nilai angka iod maka semakin besar pula daya adsorbsi dari adsorben. Daya serap karbon terbagi 2 yaitu :

a. Daya serap fisika (adsorbsi fisika)

Biasanya melibatkan perubahan energi yang lebih kecil (ikatan lemah)

Contoh : adsorbsi $\mathrm{N}_{2}$ pada karbon melepas \pm $5000 \mathrm{kal} / \mathrm{mol}$

b. Daya serap kimia (adsorbsi kimia)

Pada suhu tinggi atom $\mathrm{C}$ bergabung dengan $\mathrm{O}_{2}$ membentuk $\mathrm{CO}$ dan $\mathrm{CO}_{2}$ [4].

\section{Metodologi Penelitian}

Penelitian mengenai adsorben alternatif dari batang jagung ini dilakukan dengan tahapan aktivasi, penentuan bilangan iodine dan tahap analisis. Pada tahap analisis dilakukan dengan tahapan analisa larutan blanko, penentuan kadar klorin sebelum penambahan adsorben, dan penentuan kadar klorin setelah penambahan adsorben dari batang jagung.

Pada tahap aktivasi bahan dasar (batang jagung) dikeringkan dan dipotong kecil - kecil $( \pm$ $0.5 \mathrm{~cm})$, Diblender. diayak dengan ukuran masing - masing 50 dan 75 mesh. Sebanyak 1000 gram tepung jagung ditambahkan dengan aktivator $\mathrm{H}_{2} \mathrm{SO}_{4}$ dengan konsentrasi masing masing $1 \%$, 3\%, dan 5\% sampai seluruhnya terendam, dibiarkan selama 24 jam. Hasil rendaman batang jangung dengan aktivator dicuci sampai tidak terdapat sisa asam dan dikeringkan di udara terbuka lalu dimasukkan kedalam oven dengan suhu $105{ }^{\circ} \mathrm{C}$ selama 24 jam.

Masing - masing adsorben yang telah terbentuk ditentukan bilangan iodinnya dengan cara sebanyak 1 gram adsorben dari batang jagung ditimbang dan dikeringkan pada suhu $110^{\circ} \mathrm{C}$ selama 3 jam. Dilakukan pendinginan dalam desikator. Selanjutnya ditambahkan 50 $\mathrm{mL}$ larutan iod $0,1 \mathrm{~N}$ dan diaduk dengan magnetic stirer selama 15 menit. Disaring dan diambil sebanyak $10 \mathrm{~mL}$ filtrat. Dititrasi dengan larutan $\mathrm{Na}_{2} \mathrm{~S}_{2} \mathrm{O}_{3} \quad 0,1 \mathrm{~N}$ sampai warna kuning berkurang. Selanjutnya ditambahkan beberapa tetes indikator amilum $1 \%$ dan dititrasi kembali sampai larutan tidak berwarna, dicatat volume $\mathrm{Na}_{2} \mathrm{~S}_{2} \mathrm{O}_{3} \quad 0,1 \quad \mathrm{~N}$ yang terpakai. Titrasi juga dilakukan untuk larutan blanko.

Setelah diperoleh bilangan iodine dari masing - masing adsorben, lalu dianalisa kemampuan penyerapannya terhadap klorin dalam air olahan (treated water). Tahap analisa yang dilakukan pada percobaan dengan prosedur tittrasi iodometri, dan terdiri dari tiga tahap, yaitu berupa analisa larutan blanko, analisa kadar klorin sebelum adsorbsi dan sesudah adsorbsi.

Penentuan klor aktif sebagai $\mathrm{mg} \mathrm{Cl}_{2} / \mathrm{l}$ dapat dilihat pada persamaan 1 :

$$
\mathrm{Cl}_{2} / \mathrm{l}=\frac{(\mathrm{A}-\mathrm{B}) \cdot \mathrm{N} \cdot 35453}{\mathrm{~V}}
$$

Keterangan :

$\mathrm{A}=\mathrm{ml}$ titran $\mathrm{Na}_{2} \mathrm{~S}_{2} \mathrm{O}_{3}$ untuk sampel

$\mathrm{B}=$ ml titran $\mathrm{Na}_{2} \mathrm{~S}_{2} \mathrm{O}_{3}$ 0,01 untuk blanko (bisa positif atau negatif

$\mathrm{N}=$ Normaliti larutan titran $\mathrm{Na}_{2} \mathrm{~S}_{2} \mathrm{O}_{3}$

$\mathrm{V}=$ volume sampel $(\mathrm{ml})$

\section{Hasil dan Pembahasan}

Parameter yang dapat menunjukkan kualitas karbon aktif adalah daya adsorbsi terhadap larutan iod. Semakin besar bilangan iodnya semakin besar kemampuan dalam mengadsorbsi adsorbat atau zat terlarut. Hasil dari penentuan bilangan iodin terlihat pada gambar 1, dimana terlihat bilangan iodin terbaik diperoleh pada konsentrasi aktivator $\mathrm{H}_{2} \mathrm{SO}_{4} 5 \%$ dan ukuran partikel 70 mesh dengan jumlah $482,33 \mathrm{mg} / \mathrm{l}$.

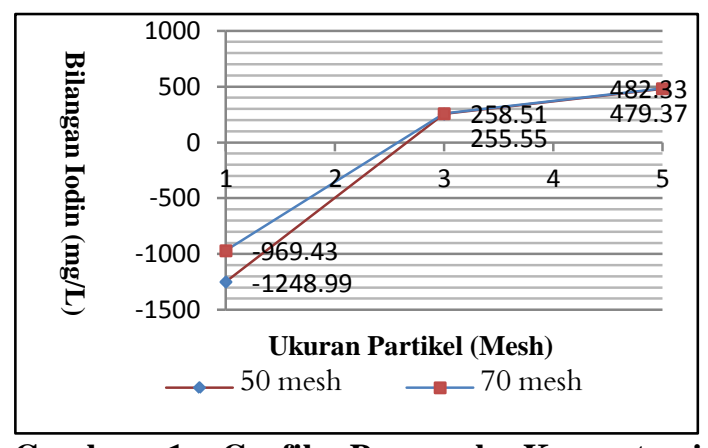

Gambar 1. Grafik Pengaruh Konsentrasi Aktivator $\mathrm{H}_{2} \mathrm{SO}_{4}$ dan Ukuran Partikel Adsorben Terhadap Bilangan Iodin 
Tabel 1 terlihat untuk konsentrasi aktivator sebesar $1 \%$ diperoleh hasil negatif terhadap bilangan iodin hal ini disebabkan karena pori - pori dari adsorben belum berkembang dengan baik, sehingga belum mampu menyerap iodin. Seiring dengan meningkatnya konsentrasi aktivator menunjukkan juga peningkatan daya serap terhadap iodin yang menandakan pori - pori sudah berkembang lebih baik.
Tabel 1. Hasil Perhitungan Bilangan Iodin

\begin{tabular}{|c|c|r|}
\hline $\begin{array}{c}\text { Konsentrasi } \\
\text { Aktivator } \\
\mathbf{H}_{\mathbf{2}} \mathbf{S O}_{\mathbf{4}} \mathbf{( \% )}\end{array}$ & $\begin{array}{c}\text { Ukuran } \\
\text { partikel } \\
\text { (mesh) }\end{array}$ & $\begin{array}{c}\text { Bilangan Iodin } \\
\text { (mg/l) }\end{array}$ \\
\hline \multirow{2}{*}{1} & 50 & - \\
\cline { 2 - 3 } & 70 & - \\
\hline \multirow{2}{*}{3} & 50 & 969.43 \\
\cline { 2 - 3 } & 70 & 255.55 \\
\hline \multirow{2}{*}{5} & 50 & 258.51 \\
\cline { 2 - 3 } & 70 & 479.37 \\
\hline
\end{tabular}

Tabel 2. Hasil Analisa Kadar Klorin Dalam Sampel

\begin{tabular}{|c|c|c|c|c|c|c|}
\hline $\begin{array}{c}\text { Konsentrasi } \\
\text { aktivator } \\
(\%)\end{array}$ & $\begin{array}{l}\text { Ukuran } \\
\text { partikel }\end{array}$ & $\begin{array}{c}\text { Massa } \\
\text { adsorben } \\
\text { (gram) }\end{array}$ & $\begin{array}{l}\text { Volume } \\
\text { larutan } \\
\text { blanko }\end{array}$ & $\begin{array}{c}\text { Volume } \\
\mathrm{Na}_{2} \mathrm{SO}_{4} \\
\text { blanko } \\
\text { (ml) }\end{array}$ & $\begin{array}{l}\text { Volume } \\
\mathbf{I}_{2}(\mathrm{ml})\end{array}$ & $\begin{array}{c}\text { Volume } \\
\text { titran } \\
\mathrm{Na}_{2} \mathrm{~S}_{2} \mathrm{O}_{3}(\mathrm{ml}) \\
\text { sampel }\end{array}$ \\
\hline \multirow{8}{*}{$1 \%$} & \multirow{3}{*}{50} & \multirow{3}{*}{1} & \multirow{3}{*}{100} & \multirow{3}{*}{6,96} & \multirow{3}{*}{50} & 14.5 \\
\hline & & & & & & 14.6 \\
\hline & & & & & & 14.7 \\
\hline & \multicolumn{5}{|c|}{ Rata - rata } & 14.6 \\
\hline & \multirow{3}{*}{50} & \multirow{3}{*}{1} & \multirow{3}{*}{100} & \multirow{3}{*}{6,96} & \multirow{3}{*}{50} & 16.8 \\
\hline & & & & & & 16.7 \\
\hline & & & & & & 16.9 \\
\hline & \multicolumn{5}{|c|}{ Rata - rata } & 16.8 \\
\hline \multirow{8}{*}{$3 \%$} & \multirow{3}{*}{50} & \multirow{3}{*}{1} & \multirow{3}{*}{100} & \multirow{3}{*}{6,96} & \multirow{3}{*}{50} & 4.94 \\
\hline & & & & & & 4.96 \\
\hline & & & & & & 4.94 \\
\hline & \multicolumn{5}{|c|}{ Rata - rata } & 4.95 \\
\hline & \multirow{3}{*}{70} & \multirow{3}{*}{1} & \multirow{3}{*}{100} & \multirow{3}{*}{6,96} & \multirow{3}{*}{50} & 4.91 \\
\hline & & & & & & 5.1 \\
\hline & & & & & & 4.76 \\
\hline & \multicolumn{5}{|c|}{ Rata - rata } & 4.92 \\
\hline \multirow{8}{*}{$5 \%$} & \multirow{3}{*}{50} & \multirow{3}{*}{1} & \multirow{3}{*}{100} & \multirow{3}{*}{6,96} & \multirow{3}{*}{50} & 3,17 \\
\hline & & & & & & 3,18 \\
\hline & & & & & & 3,20 \\
\hline & \multicolumn{5}{|c|}{ Rata - rata } & 3,18 \\
\hline & & & & & & 3,18 \\
\hline & 70 & 1 & 100 & 6,96 & 50 & 3,15 \\
\hline & & & & & & 3,15 \\
\hline & & & ata - rat & & & 3,16 \\
\hline
\end{tabular}

Tabel 2 menunjukkan hasil dari analisa adsorben terhadap klorin yang terdapat dalam air olahan. Pada gambar 2 terlihat untuk konsentrasi aktivator sebesar 3\% hasil persentase klorin yang diserap diperoleh sebesar 66,20\% sehingga klorin yang tersisa pada sampel adalah sebesar 2,37 mg/l. terlihat pula dengan semakin meningkatnya jumlah karbon aktif yang ditambahkan daya serapnya juga ikut meningkat.

Pada gambar 3 untuk konsentrasi aktivator sebesar 5\% terlihat kadar klorin yang terserap pada waktu adsorbsi 90 menit dan massa adsorben 150 gram sampai dengan 96,08\% sehingga klorin yang tersisa dalam sampel adalah sebesar 0,46 mg/l dimana kadar tersebut sudah memenuhi standar baku mutu air yang ditetapkan. 


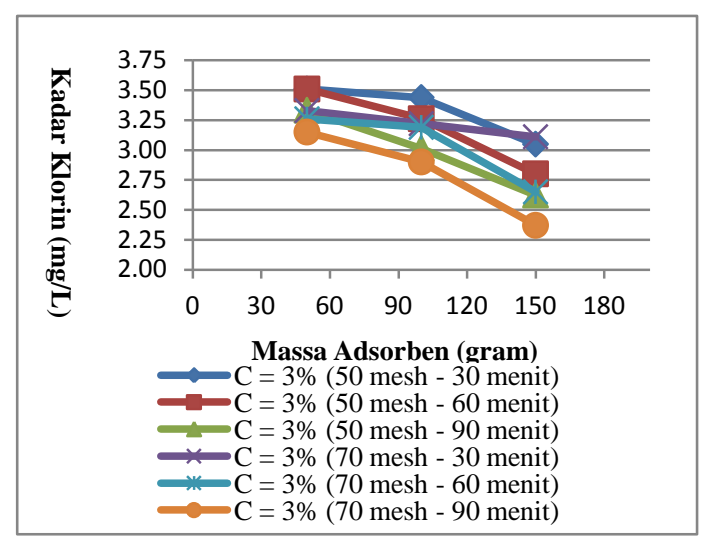

Gambar 2. Grafik Pengaruh Penambahan Adsorben Terhadap Kadar Klorin Dalam Sampel Dengan Konsentrasi Aktivator 3\%

\section{Kesimpulan}

Dari hasil penelitian diperolah kondisi yang terbaik adsorben dalam mengadsorbsi klorin yaitu pada ukuran partikel 70 mesh dan konsentrasi aktivator 5\% dengan lama waktu adsorbsi 90 menit, dimana jumlah bilangan iodine yang dihasilkan adalah sebesar 482,33 $\mathrm{mg} / \mathrm{l}$. hasil penelitian menunjukkan kondisi terbaik adsorbsi, diperoleh kadar klorin yang dapat diserap oleh adsorben adalah sebesar 3,44 $\mathrm{mg} / \mathrm{l}$ atau sebesar 96,08 \%. Kadar klorin yang tersisa setelah terjadi proses adsorbsi adalah sebesar $0,46 \mathrm{mg} / \mathrm{l}$ dan telah memenuhi standar kualitas baku mutu air olahan yang ditetapkan. Berdasarkan hasil diatas, menunjukkan bahwa limbah batang jagung dapat diolah menjadi salah satu adsorben alternatif yang difungsikan untuk mengadsorbsi klorin yang terlarut dalam air olahan (treated water).

\section{Daftar Pustaka}

[1] Alaerts, G, Metoda Penelitian Air, Penerbit Usaha Nasional, Surabaya, 1987.

[2] Dedi, S dan Gunawan, E, Pembuatan Arang Aktif dari Batang Jagung Menggunakan Aktivator Asam Sulfat dan Penggunaannya pada Penjerapan Ion Tembaga (II), Jurnal Makara Sains Vol 14 No.1, Jakarta, 2010.

[3] Djatmiko, B dkk, Arang : Pengolahan dan Kegunaannya, Penerbit Fateta IPB, Bogor, 1981.

[4] Ketaren, S, Kimia Minyak dan Lemak, Penerbit UI Press, Jakarta, 2003.

[5] Othmer, D.F And G.A. Fermstrom, Distillation of Bagasse, International Chemical Engineering Journal, 1941.

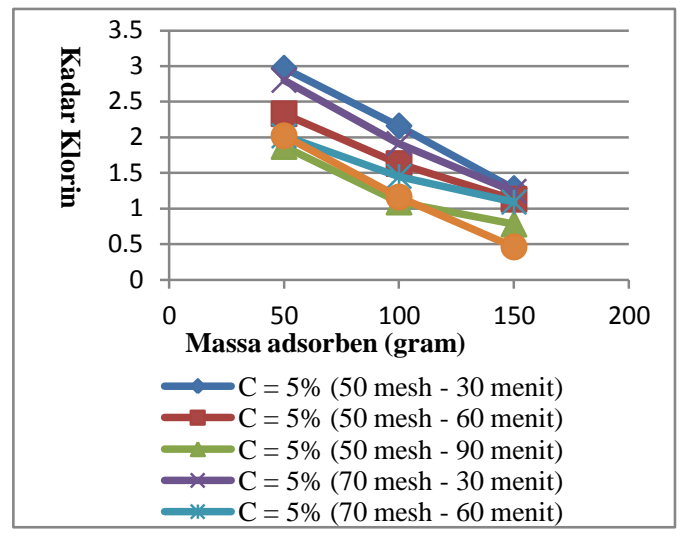

Gambar 3. Grafik Pengaruh Penambahan Adsorben Terhadap Kadar Klorin Dalam Sampel Dengan Konsentrasi Aktivator 5\%

[6] Saputro, M, Pembuatan Karbon Aktif dari Kulit Kacang Tanah (Arachis Hypogeae) dengan Aktivator Asam Sulfat, Laporan Tugas Akhir, Universitas Diponegoro, Semarang, 2010.

[7] Widyastuti, dkk, Karakteristik Karbon Aktif dari Alang - Alang yang Dibuat dengan Cara Kimia, Laporan Penelitian, Fakultas Teknik, Universitas Setia Budi, Mojosongo, 2008. 